\title{
Supratentorial non-RELA, ZFTA-fused ependymomas: a comprehensive phenotype genotype correlation highlighting the number of zinc fingers in ZFTA-NCOA $1 / 2$ fusions
}

Arnault Tauziède-Espariat ${ }^{1,2,3^{*}+}$, Aurore Siegfried ${ }^{4,5,6 \dagger}$, Yvan Nicaise ${ }^{5,6}$, Thomas Kergrohen ${ }^{7,8}$, Philipp Sievers ${ }^{9,10}$, Alexandre Vasiljevic ${ }^{11}$, Alexandre Roux ${ }^{3,12}$, Edouard Dezamis ${ }^{12}$, Chiara Benevello ${ }^{12}$, Marie-Christine Machet ${ }^{13}$, Sophie Michalak ${ }^{14}$, Chloe Puiseux ${ }^{15}$, Francisco Llamas-Gutierrez ${ }^{15}$, Pierre Leblond ${ }^{16}$, Franck Bourdeaut ${ }^{17}$, Jacques Grill ${ }^{8,18}$, Christelle Dufour ${ }^{8,18}$, Léa Guerrini-Rousseau ${ }^{8,18}$, Samuel Abbou ${ }^{8}$, Volodia Dangouloff-Ros ${ }^{3,19,20,}$ Nathalie Boddaert ${ }^{3,19,20}$, Raphaël Saffroy ${ }^{21}$, Lauren Hasty' ${ }^{1}$ Ellen Wahler ${ }^{1}$, Mélanie Pagès ${ }^{1}$, Felipe Andreiuolo ${ }^{1}$, Emmanuèle Lechapt ${ }^{1,3}$, Fabrice Chrétien 1,3, Thomas Blauwblomme ${ }^{22}$, Kévin Beccaria ${ }^{22}$, Johan Pallud 2,3,12, Stéphanie Puget ${ }^{22}$, Emmanuelle Uro-Coste ${ }^{4,5,6 \dagger}$ and Pascale Varlet ${ }^{1,2,3 \dagger}$, on behalf of the RENOCLIP-LOC the BIOMECA (Biomarkers for Ependymomas in Children, Adolescents) consortium

\begin{abstract}
The CIMPACT-NOW Update 7 has replaced the WHO nosology of "ependymoma, RELA fusion positive" by "Supratentorial-ependymoma, C110rf95-fusion positive". This modification reinforces the idea that supratentorial-ependymomas exhibiting fusion that implicates the C110rf95 (now called ZFTA) gene with or without the RELA gene, represent the same histomolecular entity. A hot off the press molecular study has identified distinct clusters of the DNA methylation class of ZFTA fusion-positive tumors. Interestingly, clusters 2 and 4 comprised tumors of different morphologies, with various ZFTA fusions without involvement of RELA. In this paper, we present a detailed series of thirteen cases of nonRELA ZFTA-fused supratentorial tumors with extensive clinical, radiological, histopathological, immunohistochemical, genetic and epigenetic (DNA methylation profiling) characterization. Contrary to the age of onset and MRI aspects similar to RELA fusion-positive EPN, we noted significant histopathological heterogeneity (pleomorphic xanthoastrocytoma-like, astroblastoma-like, ependymoma-like, and even sarcoma-like patterns) in this cohort. Immunophenotypically, these NFKB immunonegative tumors expressed GFAP variably, but EMA constantly and L1CAM frequently. Different gene partners were fused with ZFTA: NCOA1/2, MAML2 and for the first time MN1. These tumors had epigenetic homologies within the DNA methylation class of ependymomas-RELA and were classified as satellite clusters 2 and 4. Cluster $2(n=9)$ corresponded to tumors with classic ependymal histological features $(n=4)$ but also had astroblastic features $(n=5)$. Various types of ZFTA fusions were associated with cluster 2 , but as in the original report, ZFTA:MAML2
\end{abstract}

\footnotetext{
*Correspondence: a.tauziede-espariat@ghu-paris.fr

${ }^{\dagger}$ Arnault Tauziède-Espariat, Aurore Siegfried, Emmanuelle Uro-Coste and Pascale Varlet have contributed equally to this work

1 Department of Neuropathology, GHU Paris-Psychiatrie et Neurosciences, Sainte-Anne Hospital, 1, rue Cabanis, 75014 Paris, France

Full list of author information is available at the end of the article
}

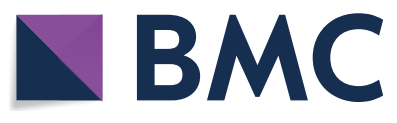

(c) The Author(s) 2021. Open Access This article is licensed under a Creative Commons Attribution 4.0 International License, which permits use, sharing, adaptation, distribution and reproduction in any medium or format, as long as you give appropriate credit to the original author(s) and the source, provide a link to the Creative Commons licence, and indicate if changes were made. The images or other third party material in this article are included in the article's Creative Commons licence, unless indicated otherwise in a credit line to the material. If material is not included in the article's Creative Commons licence and your intended use is not permitted by statutory regulation or exceeds the permitted use, you will need to obtain permission directly from the copyright holder. To view a copy of this licence, visit http://creativecommons.org/licenses/by/4.0/. The Creative Commons Public Domain Dedication waiver (http://creativecommons.org/publicdomain/zero/1.0/) applies to the data made available in this article, unless otherwise stated in a credit line to the data. 
fusion was frequent. Cluster 4 was enriched with sarcoma-like tumors. Moreover, we reported a novel anatomy of three ZFTA:NCOA1/2 fusions with only 1 ZFTA zinc finger domain in the putative fusion protein, whereas all previously reported non-RELA ZFTA fusions have 4 ZFTA zinc fingers. All three cases presented a sarcoma-like morphology. This genotype/phenotype association requires further studies for confirmation. Our series is the first to extensively characterize this new subset of supratentorial ZFTA-fused ependymomas and highlights the usefulness of ZFTA FISH analysis to confirm the existence of a rearrangement without RELA abnormality.

Keywords: Ependymoma, ZFTA, RELA, DNA-methylation, Clusters

\section{Background}

Ependymomas (EPN) are glial neoplasms that affect mainly children and young adults. New insights in the genomic and epigenetic landscape of EPN has led to the identification of different groups accordance to their anatomic location (supratentorial, posterior fossa and spinal) [1]. Three subgroups have been identified among supratentorial tumors (ST-EPN): subependymomas; EPN, YAP1 fusion-positive; and EPN, RELA fusion-positive (according to the World Health Organization-WHO-2016 classification) [1-4]. Infrequently (6.5\% of cases in one series) [4], C11orf95 or RELA genes have fused with other genes as a result of chromothripsis. The Consortium to Inform Molecular and Practical Approaches to CNS Tumor Taxonomy (c-IMPACT NOW) Update 7 recently proposed the nosology "ST-EPN, C11orf95-fusion positive" instead of "ST-EPN, RELA-fusion positive" [5]. This modification reinforces the idea that when STEPN exhibits fusion that implicates the C11orf95 gene with or without the RELA gene, it represents the same histomolecular entity [4, 6-8]. In recent papers, the methylation classifier based on Forest plot random classification highighted that cases with C11orf95fusion without $R E L A$ presented epigenetic vicinity with tumors of the EPN-RELA methylation class (MC) and subdivided them into two satellite clusters (2 and 4 ) by multidimensional reductionality (more specifically t-Distributed Stochastic Neighbor Embedding (t-SNE) analysis) $[8,9]$. However, these alternative partners to RELA seem to produce original morphological patterns which challenge the histopathological diagnosis. In fact, recent studies have reported a large spectrum of morphologies, including glial, glioneuronal, embryonal and even mesenchymal and epithelial patterns in tumors harboring C11orf95-fusions without RELA [6, $7,9]$. In this study, we performed a clinico-pathological and molecular analysis (including DNA-methylation profiling and the identification of the new clusters of methylation) of 13 new cases of ST-EPN with C11orf95 (now called ZFTA for Zing Finger Translocation Associated by the new HUGO gene Nomenclature Committee) fusion without the RELA gene to more suitably characterize these tumors and compare them with their counterparts which have classical ZFTA:RELA fusion.

\section{Methods \\ Study design, patients, data collection}

This study included patients diagnosed with ST EPN or glial ST tumors with ZFTA rearrangement but no RELA rearrangement during ependymal cell differentiation, determined by FISH analyses (techniques previously described [3]).

Epidemiological data (gender and age at diagnosis) and tumor- and treatment-related data (location of tumor and extension, extent of resection, relapses and complementary treatments) were retrospectively analyzed. The extent of the initial resection was assessed by magnetic resonance imaging (MRI) or computed tomography performed after surgery. All the patients' parents or legal guardians signed informed consent forms before treatment was started. We obtained human subjects approval from our institutional review board.

\section{Statistical analyses}

Unadjusted survival curves for overall survival (OS) and progression-free survival (PFS) were plotted using the Kaplan-Meier method and log-rank tests were used to assess the significance of group comparison. A $p$ value of less than 0.05 was considered significant. Statistical analyses were performed using JMP software (version 14.3.0, SAS Institute Inc, Cary, USA). We pooled our data with that of previously reported cases of ST non-RELA ZFTAfused EPN [6-8] and compared them to the data in the literature concerning known EPN with ZFTA:RELA fusion, and the other histopathological differential diagnoses such as EPN, YAP1-fusion positive, HGNET$B C O R$, and HGNET-MN1 [2, 3, 10-22].

\section{Central radiological review}

The central radiological review was performed by two neuroradiologists (NB and VDR). Preoperative MRIs were read and the following features were analyzed: location, tumor size, signal in a T1-weighted sequence and a T2-weighted sequence, susceptibility imaging, the diffusion and apparent diffusion coefficient map (ADC), 
enhancement, presence of cysts, necrosis, and perfusion parameters.

\section{Central histopathological review}

The central pathology review was performed conjointly by two neuropathologists (ATE and PV).

\section{Immunohistochemistry}

Unstained 3- $\mu$ m-thick slides of formalin-fixed, paraffin-embedded tissues were obtained and submitted for immunostaining with an automated stainer (Dako Omnis, Glostrup, Denmark). The following primary antibodies were used: CD56 (pre-diluted, clone 123C3, Dako, Glostrup, Denmark), Glial Fibrillary Acidic Protein (GFAP) (1:200, clone 6F2, Dako, Glostrup, Denmark), Olig2 (1:500, clone OLIG2, Sigma-Aldrich, Saint-Louis, USA), vimentin (1:800, clone V9, Dako, Glostrup, Denmark), neurofilament (1:100, clone NF70, Dako, Glostrup, Denmark), NeuN (1:1000, clone A60, Sigma-Aldrich, Saint-Louis, USA), synaptophysin (1:150, clone Synap, Dako, Glostrup, Denmark), EMA (1:200, clone GM008, Dako, Glostrup, Denmark), CK18 (1:200, clone 6F2, Dako, Glostrup, Denmark), smooth muscle actin (1:4000, clone 1A4, Dako, Glostrup, Denmark), NFкB (1:6000, clone D14E12, Cell Signaling Technology, Danvers, USA), L1CAM (1:500, clone UJ127.11, SigmaAldrich, Saint-Louis, USA), and Ki-67 (1:200, clone MIB1, Dako, Glostrup, Denmark). Reticulin staining was performed using the Reticulin silver plating kit according to Gordon \& Sweets (Merck Millipore, Guyancourt, France). External positive and negative controls were used for all antibodies and staining.

\section{FISH analyses}

A FISH study was performed on interphase nuclei according to the standard procedures and the manufacturer's instructions. The CDKN2A gene copy number was assessed using the following centromeric and locus specific probes: Vysis CDKN2A/CEP9 FISH Probe Kit (Abbott Molecular, USA).

Deletion was considered if they were detected in more than $30 \%$ of nuclei respectively. Results were recorded using a DM600 imaging fluorescence microscope (Leica Biosystems, Richmond, IL) fitted with appropriate filters, a CCD camera, and digital imaging software from Leica (Cytovision, v7.4).

\section{DNA sequencing}

Mutations for the $h T E R T$ promoter was developed using Massarray iPlex technology and Massarray online design tools (Agena Bioscience) as previously described [23].

\section{RNA sequencing}

RNA was isolated from FFPE (Formalin-fixed paraffinembedded) tissues with sufficient tumoral density. RNA was extracted using the High Pure FFPET RNA Isolation Kit (catalogue \# 06650775001 Roche diagnostics GmbH) according to the manufacturer's instructions. The RNA concentrations were measured on a Qubit 4 Fluorometer (\# Q33238, Thermo Fisher Scientific) with the Invitrogen Qubit RNA BR Kit (\# Q10210, Thermo Fisher Scientific). The percentage of RNA fragments $>200$ nt (fragment distribution value; DV200) was evaluated by capillary electrophoresis (Agilent 2100 Bioanalyzer). DV200 > 30\% was required to process the next steps in the analysis. NGSbased RNA sequencing was performed using the Illumina TruSight RNA Fusion Panel on a Nextseq550 instrument according to the manufacturer's instructions (Illumina, San Diego, CA, USA). This targeted RNA sequencing panel covers 507 fusion-associated genes, to assess the most recognized cancer-related fusions. The TruSight RNA fusion panel gene list is available at https://www. illumina.com/content/dam/illumina-marketing/docum ents/products/gene_lists/gene_list_trusight_rna_fusion panel.xlsx. 7690 exonic regions are targeted with 21,283 probes. Libraries were prepared according to the Illumina instructions for the TruSight RNA fusion Panel kit. STAR_v2.78a and Bowtie software were used to produce aligned readings in relation to the Homo Sapiens Reference Genome (UCSC hg19). Manta v1.4.0, Tophat2 and Arriba v2.1.0 tools were used for fusion calling.

\section{RT-PCR and Sanger sequencing}

RT-PCR: $1 \mu \mathrm{g}$ of total RNA was retrotranscribed with the primeScript RT Reagent kit (\# RR037A, TAKARA). RTPCR was performed using the Type-it HRM PCR Kit (\# 206544, Qiagen $\mathrm{GmbH}$ ). The primer pairs used for the MN1-C11orf95 fusion confirmation RNASeq results by qPCR were: MN1-F1: 5'-CCTGGGAGAAGGCCAAAC C-3', C11orf95-R1: 5'-CCCCAGGACCCCAAGGCA-3' (Amplicon size $=85 \mathrm{pb}$ ) and the primer pairs used for the MN1-C11orf95 fusion confirmation RNASeq results by Sanger were: MN1-F3: 5'-GCACCATTGACCTGGACT CG-3', C11orf95-R3: 5'-GGCCTCACAGTGGTCTG-3' (Amplicon size $=266 \mathrm{pb})$. Amplification conditions were $95{ }^{\circ} \mathrm{C}-5 \min \left(95{ }^{\circ} \mathrm{C}-10 \mathrm{~s} / 60{ }^{\circ} \mathrm{C}-30 \mathrm{~s} / 72{ }^{\circ} \mathrm{C}-10 \mathrm{~s}\right)$ for 45 cycles. PCRs were performed on a Rotor Gene Q (Qiagen $\mathrm{GmbH}$ ).

\section{DNA methylation profiling}

Tumor DNA was extracted from freshly frozen tissue samples using the Qiagen DNeasy Blood \& Tissue Kit (Cat NO./ID 69504) according to the manufacturer's instructions. $500 \mathrm{ng}$ of DNA were extracted from each 
tissue sample. DNA was sent to the Genotyping facility at the German Cancer Research Center (Heidelberg, Germany). All patient samples were analyzed using either Illumina Infinium Methylation EPIC or HumanMethylation 450 BeadChip arrays according to the manufacturer's instructions. Affiliation predictions were obtained from a DNA methylation-based classification web platform for central nervous system tumors (www.molecularn europathology.org, version 11b4). Next, a t-SNE analysis was performed and compared with the genome-wide DNA methylation profiles from the brain tumor reference cohort [24] as well as with a previous series of ZFTA:RELA-fused EPN [3] and with the series of ZFTAfused ependymomas reported by Zheng et al. [9]. Data was generated at the DKFZ Genomics and Proteomics Core Facility (Heidelberg, Germany) as previously described [24].

\section{Results}

\section{Clinical and radiological characteristics}

Relevant clinical data are summarized in Table 1. The median age at diagnosis was 6.7 years (patients' ages ranged from 9 months to 41 years). The male/female sex ratio was 1.6 (8 males and 5 females). Tumor locations varied; the frontal lobe being the most common location (6/13 cases, $46 \%)$. Detailed MRIs were available for $12 / 13$ cases (Figs. 1, 2, 3, 4). The size of the tumor ranged from 4 to $12 \mathrm{~cm}$. Nine tumors (Cases \#1, 3, 4, 5, 8, 10, 11, 12, and 13) showed a similar imaging pattern: well-demarcated masses, located in the hemispheres with a large cystic portion, and a thick heterogeneous solid component intensely enhanced after gadolinium injection.
Peritumoral edema was always present and frequently abundant. Of the six cases with a FLAIR sequence available, two had hyperintense intracystic content (Figs. 1, 4). Conversely, the three remaining cases presented a prominent solid component without cystic content (Cases \#6, 7, and 9), mild or no peritumoral edema, and variable contrast enhancement (mild in Cases \#6 and 7, intense in Case \#9). Diffusion was restricted in $6 / 8$ patients with available sequences (Figs. 1c, 3c), and intermediate in the two remaining cases. Cerebral Blood Flow using Arterial Spin Labelling (ASL) was intermediate (maximal value in the tumor: 50 to $56 \mathrm{~mL} / \mathrm{min} / 100 \mathrm{~g}$ ) in $3 / 3$ cases with available sequences (Figs. 1d, 3d). All patients, except two (Cases \#1 and 9) underwent total resection. All patients, except two (Cases \#2 and 13), received adjuvant treatment (mainly conventional focal radiation therapy). Outcome data was available for all patients included in the cohort. Six (46\%) patients had tumor recurrence, with a mean PFS of 30.1 months (median 16.1 months; CI 95\%: 4-85). Two patients (Cases \#1 and 9) died of their disease, with a mean OS of 24 months. The two patients who died were those who had not undergone total resection. When we pooled our data with data from the literature, the mean/median PFS were 70.4/27.6 months for EPN, ZFTA:RELA-fused, 36.3 months/ not reached for EPN, YAP1-fusion positive, 24.4/9.2 months for ST nonRELA ZFTA-fused EPN, 43.9/34.0 months for HGNET$M N 1$ and 16.2/12.0 months for HGNET-BCOR with a significant difference in all groups on univariate analysis $(p<0.001)$. The median OS was not reached for all subgroups except for HGNET-BCOR (76.0 months) and the mean OS was not reached for the EPN, YAP1-fusion

Table 1 Case list of our series of non-RELA ZFTA fused-EPN with clinical features

\begin{tabular}{|c|c|c|c|c|c|c|}
\hline Case & Sex, age & Location & Surgery & $\begin{array}{l}\text { Adjuvant } \\
\text { treatment }\end{array}$ & $\begin{array}{l}\text { Local recurrence, } \\
\text { PFS (mo) }\end{array}$ & $\begin{array}{l}\text { Clinical } \\
\text { outcome, OS } \\
\text { (mo) }\end{array}$ \\
\hline 1 & $F, 5$ yo & Right frontal and temporal lobes & PR & CT & Yes, 5 & Dead, 42 \\
\hline 2 & M, 41 yo & Left carrefour & $\mathrm{TR}$ & No & Yes, 85 & Alive, 193 \\
\hline 3 & F, 26 yo & Right frontal and temporal lobes & $\mathrm{TR}$ & RT & No & Alive, 9 \\
\hline 4 & M, 11 yo & Left frontal and parietal lobes & $\mathrm{TR}$ & $\mathrm{RT}$ & No & Alive, 10 \\
\hline 5 & M, 8 yo & Left frontal lobe & $\mathrm{TR}$ & $C T+R T$ & No & Alive, 34 \\
\hline 6 & M, 9 yo & Right frontal lobe & $\mathrm{TR}$ & $\mathrm{RT}$ & Yes, 4 & Alive, 90 \\
\hline 7 & M, 1 yo & Left parietal and occipital lobes & $\mathrm{TR}$ & PT & No & Alive, 37 \\
\hline 8 & M, 3 yo & Right temporal and parietal lobes & $\mathrm{TR}$ & $\mathrm{RT}$ & No & Alive, 28 \\
\hline 9 & $\mathrm{~F}, 9 \mathrm{mo}$ & Right parietal lobe & PR & $\mathrm{CT}$ & Yes, 6 & Dead, 6 \\
\hline 10 & M, 26 yo & Right frontal lobe & $\mathrm{TR}$ & $C T+R T$ & No & Alive, 70 \\
\hline 11 & $\mathrm{~F}, 4$ yo & Left occipital lobe & $\mathrm{TR}$ & $\mathrm{CT}+\mathrm{PT}$ & Yes, 25 & Alive, 58 \\
\hline 12 & M, 7 yo & Right temporal, parietal and occipital lobes & $\mathrm{TR}$ & RT & No & Alive, 33 \\
\hline 13 & $\mathrm{~F}, 2$ yo & Left parietal and occipital lobes & TR & No & Yes, 53 & Alive, 115 \\
\hline
\end{tabular}




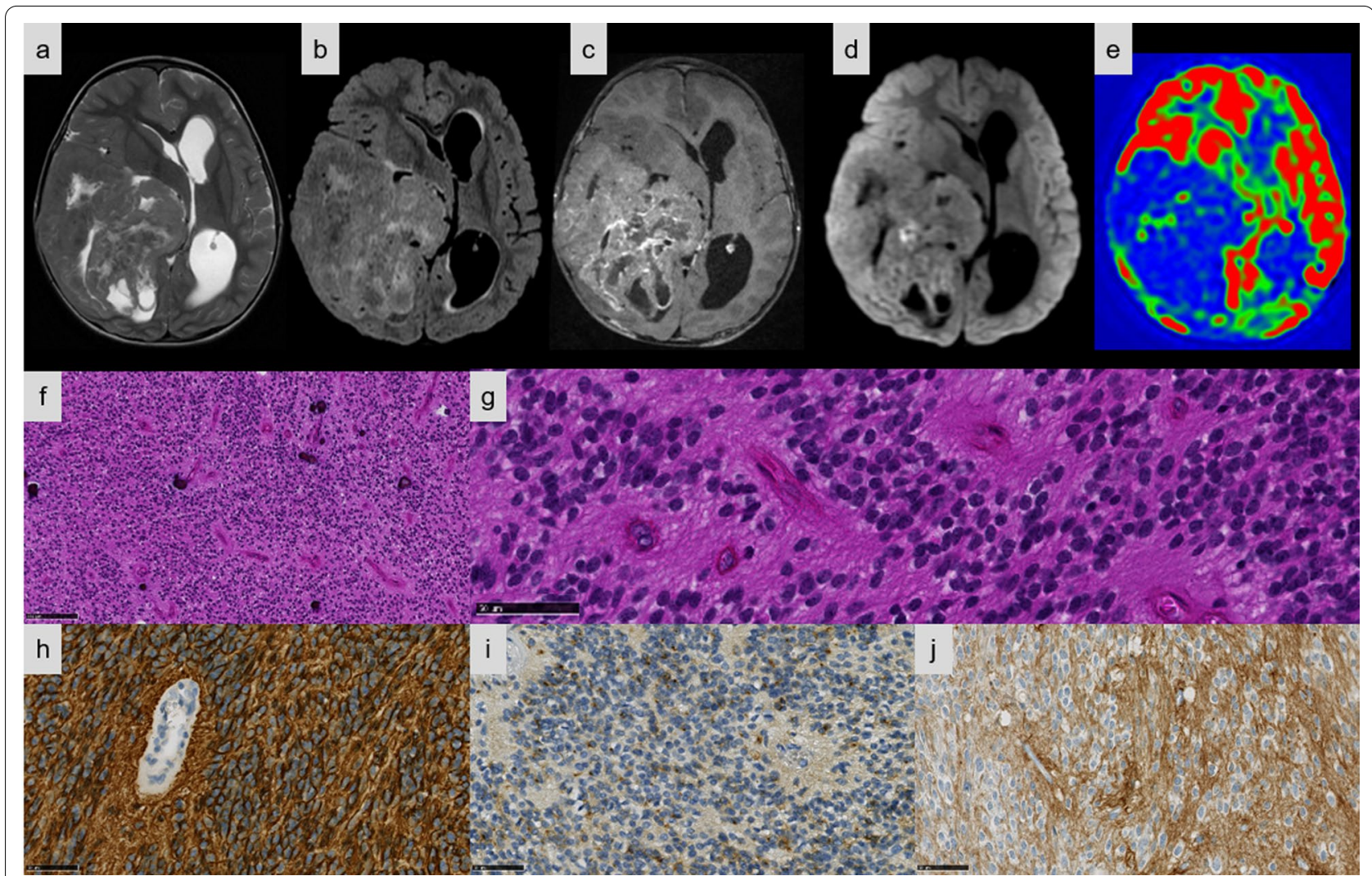

Fig. 1 Imaging and histopathological features of Case \#8. a-e Right temporo-parietal mass, mostly tissular with central necrosis. a Peripheral cysts on T2-weighted sequence. $\mathbf{b}$ Cyst content isointense on FLAIR image. c Mild heterogeneous contrast enhancement on T1-weighted sequence after gadolinium injection. $\mathbf{d}$ Diffusion restriction. e Heterogeneous tumoral blood flow with low and intermediate flow areas on Arterial Spin Labelling perfusion imaging. $\mathbf{f}$ Classical ependymoma-like pattern with calcifications (HPS, magnification $\times 100$ ). $\mathbf{g}$ Tumor with perivascular pseudorosettes (HPS, magnification $\times 400$ ). $\mathbf{h}$ Tumor with diffuse cytoplasmic immunoexpression of GFAP (magnification $\times 400$ ). i A dot-like pattern of staining for EMA in the tumor (magnification $\times 400$ ). $\mathbf{j}$ Diffuse staining for L1CAM (magnification $\times 400)$. Black scale bars represent $250 \mu \mathrm{m}(\mathbf{f})$ and $50 \mu \mathrm{m}(\mathbf{g}-\mathbf{j})$. HPS: Hematoxylin Phloxin Saffron.

positive subgroup. The mean OS were 113.5 months for ZFTA:RELA-fused EPN, 39.3 months for ST non-RELA $Z F T A$-fused EPN, 81.6 months for HGNET-MN1 and 53.2 months for HGNET-BCOR with a significant difference in all groups on univariate analysis $(p=0.003)$ (Fig. 5). Unlike OS which did not show significant differences, the PFS was significantly different between $\mathrm{ST}$ non-RELA ZFTA-fused EPN and EPN, ZFTA:RELAfused $(p=0.023)$, EPN, YAP1-fusion positive $(p<0.001)$ and HGNET-MN1 $(p=0.036)$. We found no significant difference between ST non-RELA ZFTA-fused EPN and $\operatorname{HGNET-BCOR}(p=0.700)$.

\section{Histopathological and immunohistochemical characterization}

Detailed histopathologic and immunohistochemical data are presented respectively in Additional files 1 and 2. The most predominant pattern (5/13 cases) was EPNlike, consisting of well-circumscribed tumors composed of mainly clear cells; with perivascular pseudorosettes, rosettes and delicate branching vessels demonstrating a chicken-wire appearance (Cases \#5, 6, 7, 8, and 9) (Fig. 1e-f). Another frequently observed morphological pattern was astroblastoma-like (4/13 cases), consisting of well-demarcated tumors composed of astroblastic pseudorosettes (Cases \#1, 2, 3, and 4) (Fig. 2d-f). The third histopathological pattern observed (Cases \#11, 12, and 13) was composed of spindle-shaped cells arranged in bundles with a reticulin network in two cases (Cases \#11 and 13) (Fig. 3e-f). The last tumor (Case \#10) presented a pleomorphic xanthoastrocytoma (PXA)-like morphology, composed of large pleomorphic and multinucleated cells with nuclear inclusions, associated with perivascular lymphocytic infiltrates (Fig. 4e-g). However, we observed no eosinophilic granular bodies or dense reticulin network. Calcifications were a common finding (8/13 cases, regardless of the histopathological pattern). A fibrous collagenous stroma was observed in six cases (Cases \#2, 


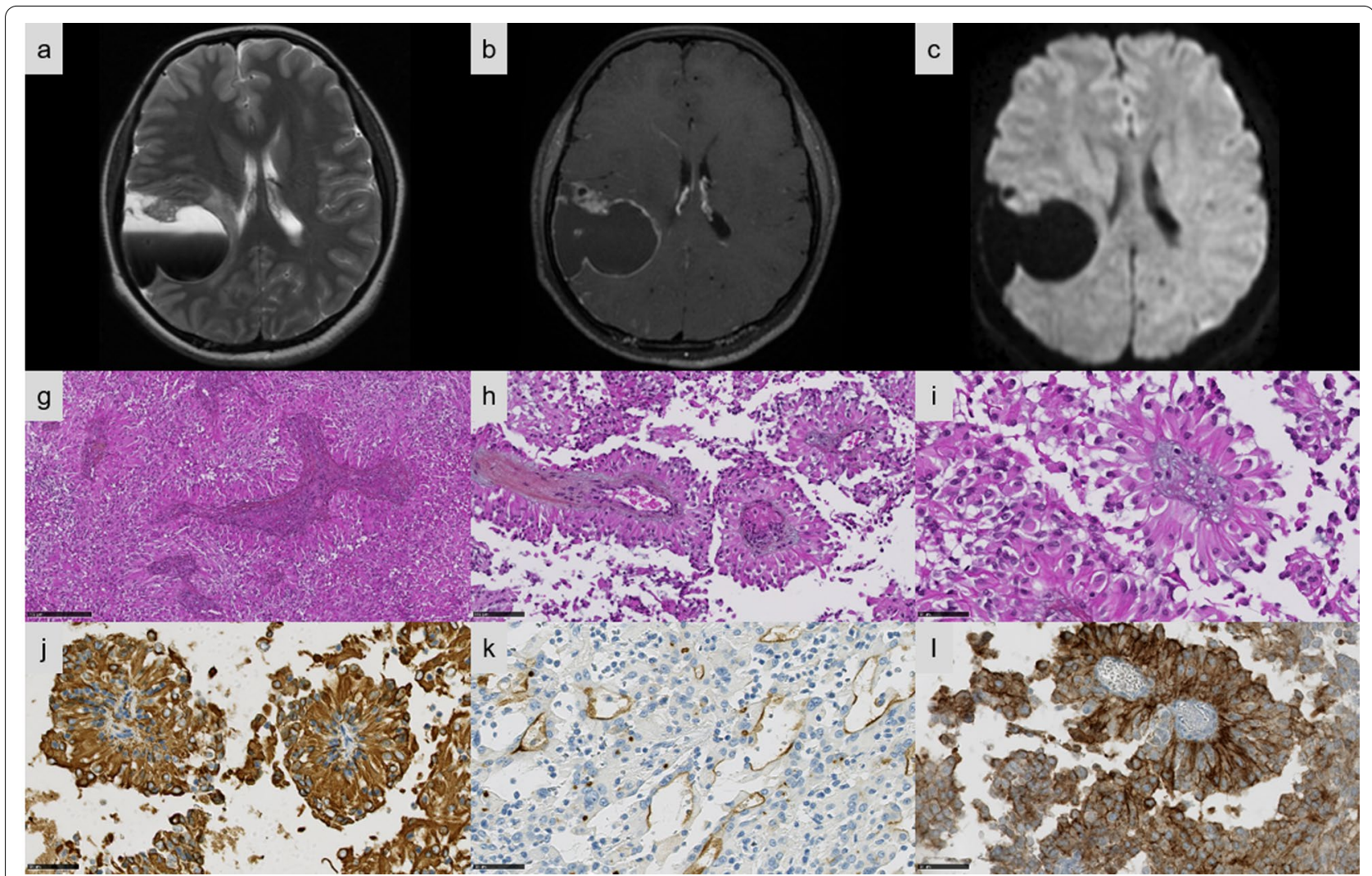

Fig. 2 Imaging and histopathological features of Case \#3. a-c Right frontotemporal cystic mass with thick walls. a Cyst fluid-fluid level on T2-weighted sequence. $\mathbf{b}$ Intense contrast enhancement of the tissular part on T1-weighted sequence after gadolinium injection. c Diffusion restriction. $\mathbf{d}$ Astroblastoma-like pattern composed of multiple pseudorosettes (HPS, magnification $\times 100)$. e Pseudorosettes composed of a central vessel and variable sclerosis (HPS, magnification $\times 200$ ). $\mathbf{f}$ Perivascular pseudorosettes composed of elongated cells containing an abundant eosinophilic cytoplasm (HPS, magnification $\times 200$ ). $\mathbf{g}$ The tumor cells strongly expressed GFAP (magnification $\times 400$ ). $\mathbf{h}$ A dot-like and apical pattern of staining for EMA in the tumor (magnification $\times 400$ ). i Diffuse staining for L1CAM (magnification $\times 400)$. Black scale bars represent $250 \mu \mathrm{m}(\mathbf{d})$, $100 \mu \mathrm{m}(\mathbf{e})$ and $50 \mu \mathrm{m}(\mathbf{f}-\mathbf{i})$. HPS: Hematoxylin Phloxin Saffron

$3,8,10,11$, and 13). Mitotic counts ranged from 2 to 102 per 10 high-power fields. In all cases except two (Cases \#2 and 13), necrosis was observed including only one case of palisading necrosis (Case \#8). Microvascular proliferation was present in all cases except one (Case \#2). All cases except one (Case \#1) exhibited CD56 staining, whereas vimentin was consistently expressed. GFAP immunoreactivity was identified in the cytoplasm and fibrillary processes of tumors with EPN-like, astroblastoma-like features (Figs. 1g, 2g), whereas no immunopositivity or only a focal expression was detected in tumors with sarcoma-like and PXA-like features (Figs. 3h, 4h). Olig2 was focally expressed in most tumors and absent in five tumors (Cases \#4, 7,11,12, and 13). Neurofilament staining confirmed the solid growth pattern of all cases (except Cases \#3 and 10, which were partially infiltrative). All cases were EMA immunopositive with varying patterns (cytoplasmic, membranous, apical, dotlike and with micro-lumens) (Figs. 1h, 2h, 3i, 4i). CK18 immunopositivity was present in 6/13 cases. Neuronal markers were positive in 11/13 cases, often only focally, without ganglion cell differentiation. Nuclear NFKB expression was only observed in a few nuclei in two tumors (Cases \#3 and 9), whereas 12/13 cases presented L1CAM immunoexpression with a mixture of varying degrees of distribution and intensity (Figs. 1i, 2i, 3j, 4j). No alpha-smooth muscle actin reactivity was identified in any case. The MIB-1 labelling index ranged from 4 to $70 \%$.

\section{Molecular results}

FISH analyses for $C D K N 2 A$ failed to reveal any deletion in any of the cases tested $(\mathrm{n}=13)$. No mutation of $h T E R T$ was evidenced in any of the cases tested $(\mathrm{n}=13)$.

We found a new MN1:ZFTA fusion which was verified by RT-PCR and Sanger sequencing for case \#2 (Additional file 3). Other ZFTA partners have been previously described [4, 6-9]. The anatomy of the 11 in 


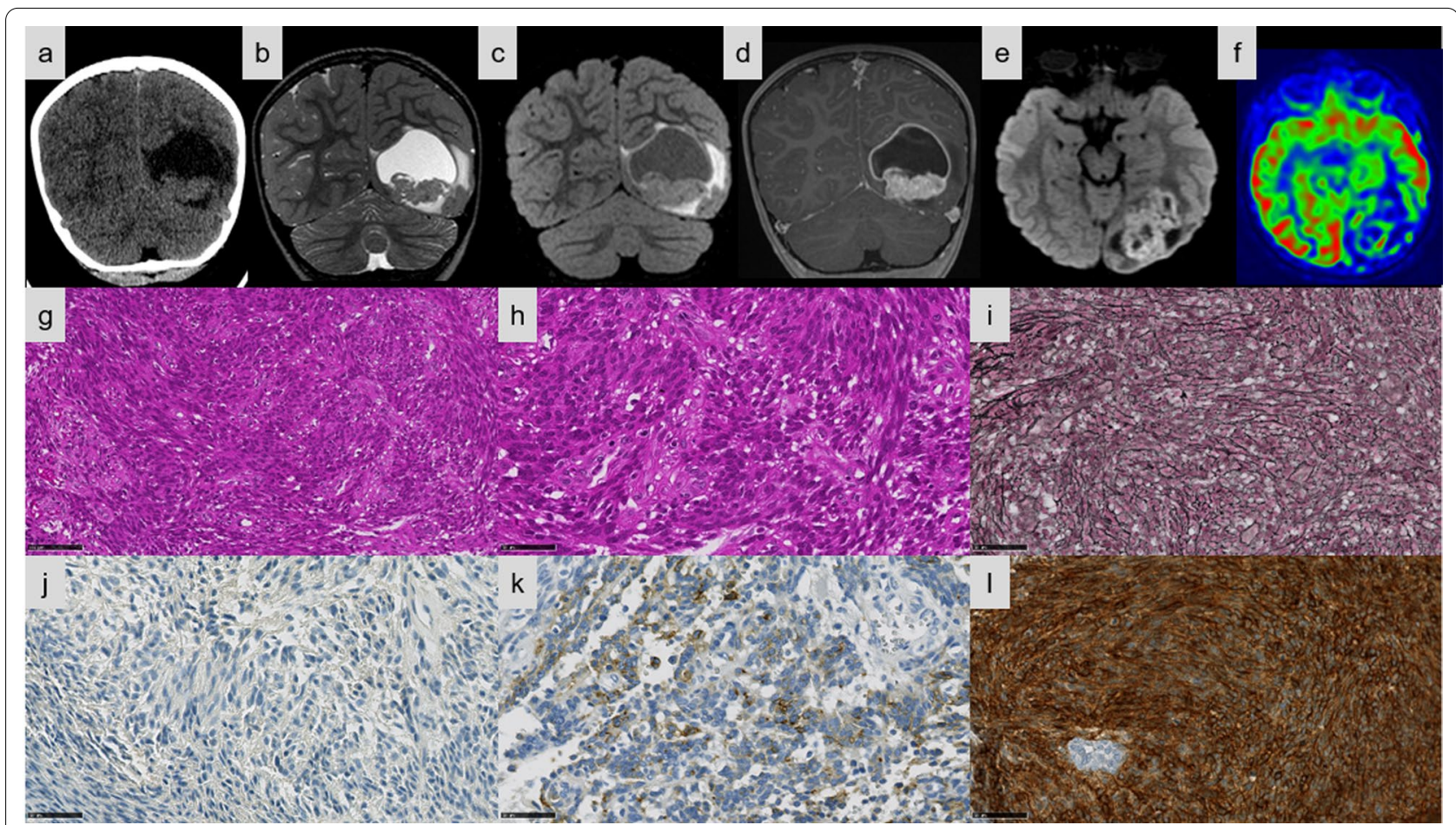

Fig. 3 Imaging and histopathological features of Case \#11. a-f Left occipital cortical cystic mass with tissular mural nodule. a Tissular part is slightly hyperdense on CT. b peritumoral edema and hyperintense cystic content on T2-weighted sequence. $\mathbf{c}$ Cyst content isointense on FLAIR image. d Intense contrast enhancement on T1-weighted sequence after gadolinium injection. e Diffusion restriction. $\mathbf{f}$ Intermediate tumoral blood flow on Arterial Spin Labelling perfusion imaging. $\mathbf{g}$ Sarcoma-like pattern composed of fascicles of spindle cells (HPS, magnification $\times 100)$. $\mathbf{h}$ Tumor composed of spindle cells (HPS, magnification $\times 400$ ). $\mathbf{i}$ Tumor with a dense reticulin network (magnification $\times 400)$. $\mathbf{j}$ The tumor cells did not express GFAP (magnification $\times 400$ ). $\mathbf{k}$ A dot-like and cytoplasmic pattern of staining for EMA in the tumor (magnification $\times 400$ ). I Diffuse staining for L1CAM (magnification $\times 400$ ). Black scale bars represent $250 \mu \mathrm{m}(\mathbf{g})$ and $50 \mu \mathrm{m}(\mathbf{h}-\mathbf{I})$. CT: computerized tomodensitometry; HPS: Hematoxylin Phloxin Saffron

frame fusions retrieved is illustrated in Fig. 6, including 3 ZFTA:MAML2 fusions, 3 ZFTA:NCOA1 fusions and 4 ZFTA:NCOA2 fusions. In case \#4, we found five spanning reads with the ZFTA mid-exon 5 joined to a non-coding intergenic region on chromosome 11 (PGRAS1(100810), TRPC6(141163)). The putative chimeric ZFTA protein essentially corresponds to a ZFTA protein truncated at its very C-terminal end, because a STOP codon is reached after only a few codons in the 3'partner sequence. Breakpoints are provided in Additional file 4. Detailed chromosomal coordinates are given using hg19. With this Illumina TruSight RNA Fusion Panel, we had only one technical failure out of 13 cases (FFPE block over 8 years old).

According to the DNA methylation-based classification and the DKFZ Classifier (version 11b4), none of the tumors were classifiable (calibrated scores for DNA methylation class $<0.9$ ). Although none of the cases received a calibrated score $\geq 0.9$ in the current version (11b4) of the CNS tumor classifier, most of the tumors obtained the highest score for ependymal subclasses
(EPN-RELA) with valid quality controls for all samples. A t-SNE analysis was performed to compare the genome-wide DNA methylation profiles of our previous EPN-RELA cohort with proven RELA:ZFTA fusion $(\mathrm{n}=80)$ [3], EPN-YAP $(\mathrm{n}=26)$, HGNET-BCOR $(\mathrm{n}=23)$ and HGNET-MN1 $(\mathrm{n}=21)$ in the CNS reference cohort [19]. All cases clustered in close proximity to EPN-RELA (Fig. 7). Copy number profiles are detailed in Additional files 5-17. In a more focused t-SNE analysis of DNA methylation data of these samples alongside the recently described satellite clusters of ZFTA-fusion positive EPN (cluster $1, \mathrm{n}=9$; cluster $2, \mathrm{n}=40$; cluster $3, \mathrm{n}=17$, and cluster $4, \mathrm{n}=27$ ) [9], four of the cases grouped with cluster 4 and nine with cluster 2 (Fig. 7).

\section{Discussion}

Like ST ZFTA:RELA-fused EPN, ST non-RELA ZFTAfused EPN affected mainly children [4, 6-8]. The sex ratio was 1.3 (13 males and 10 females) [4, 6-8]. Radiologically, non-RELA ZFTA-fused EPN presented some similarities with their classical counterparts with ZFTA:RELA 


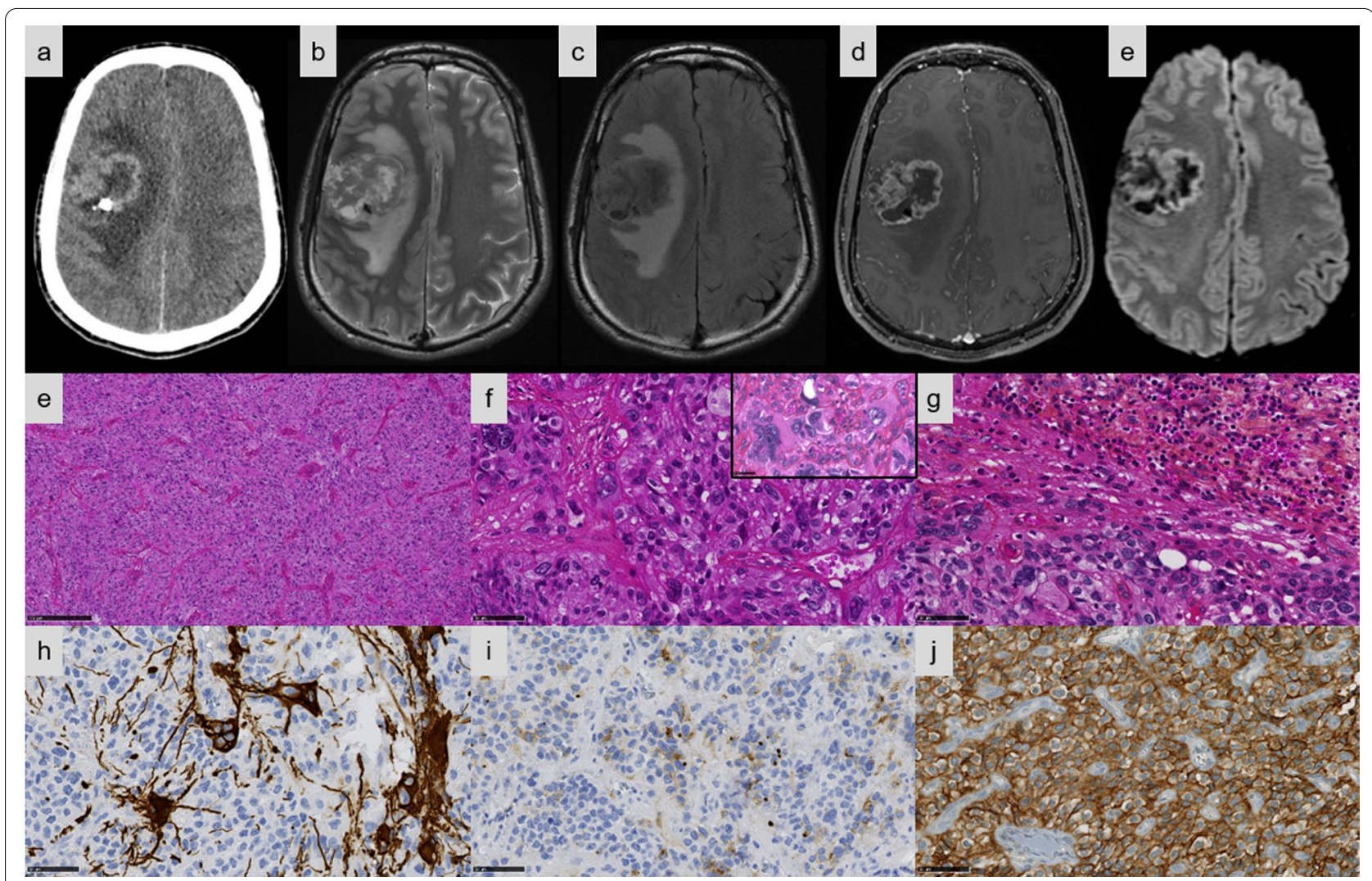

Fig. 4 Imaging and histopathological features of Case \#10. a-e Right frontal cortical tissular mass with necrosis and peripheral cysts, with abundant peritumoral edema. a The tissular part is hyperdense on CT with one macrocalcification. b Peripheral cysts with abundant peritumoral edema on T2-weighted sequence. c Cysts content hypointense on FLAIR image. $\mathbf{d}$ Intense contrast enhancement on T1-weighted sequence after gadolinium injection. e Diffusion restriction. $\mathbf{f}$ A solid tumor with a rich vascular network (HPS, magnification $\times 100$ ). $\mathbf{g}$ Tumor cells with nuclear and cytoplasmic pleomorphism with intranuclear inclusions (HPS, magnification $\times 400$ ). $\mathbf{h}$ Some focal collections of lymphocytes (magnification $\times 400$ ). $\mathbf{i}$ The proliferation presented a patchy expression for GFAP (magnification $\times 400)$. $\mathbf{j}$ A dot-like and cytoplasmic pattern of staining for EMA in the tumor (magnification $\times 400$ ). $\mathbf{k}$ Diffuse staining for L1CAM (magnification $\times 400$ ). Black scale bars represent $250 \mu \mathrm{m}(\mathbf{f})$ and $50 \mu \mathrm{m}(\mathbf{g}-\mathbf{k})$. CT: computerized tomodensitometry; HPS: Hematoxylin Phloxin Saffron.

fusion [3]. In fact, they were mainly characterized by well-demarcated solid and cystic lesions with peripheral enhancement of the cystic content [3]. However, contrary to ZFTA:RELA-fused EPN, peripheral edema was significant in our cases and for the most part the cystic component was not hyperintense on the FLAIR sequence [3]. ST non-RELA ZFTA-fused EPN presented high morphological heterogeneity with only rare cases having histopathological and immunohistochemical features of ZFTA:RELA-fused EPN [8, 9]. In the literature, their histological appearance was sarcoma-like, PXA-like, highgrade glioma-like, malignant teratoma-like, embryonal tumor-like, or had neuronal differentiation and a granular cell component $[6,7,9]$. We also identified four cases with astroblastoma-like features. Despite this phenotypical heterogeneity, all tumors were in close epigenetic proximity to the MC EPN-RELA. As expected, our cases with ZFTA fusion without RELA were subclassified in clusters 2 and 4 [9]. In the original report, the cluster 2 corresponded almost exclusively to tumors with ependymal morphology [9]. In our series, 4/9 tumors in cluster 2 showed ependymal features and 5 presented astroblastoma-like features, noted for the first time. In the original report [9], the tumors in cluster 4 corresponded to highly malignant poorly differentiated tumors including one malignant small-cell sarcomatoid carcinoma and one undifferentiated sarcoma [9]. In our series, all three tumors presenting with sarcoma histology were classified in cluster 4 . None of the cases in our series or from those in the literature exhibited significant nuclear expression of NFKB [7, 8], which supports previous studies showing that p65 immunoexpression is highly correlated to the presence of RELA fusion [3, 25, 26]. However, all except two cases $[6,7,9]$ showed L1CAM immunoexpression to varying degrees and intensities, confirmed by the RNA expression data [4]. Consequently, L1CAM may represent a diagnostic tool for non-RELA, ZFTA-fused EPN. Further immunohistochemical series including different 

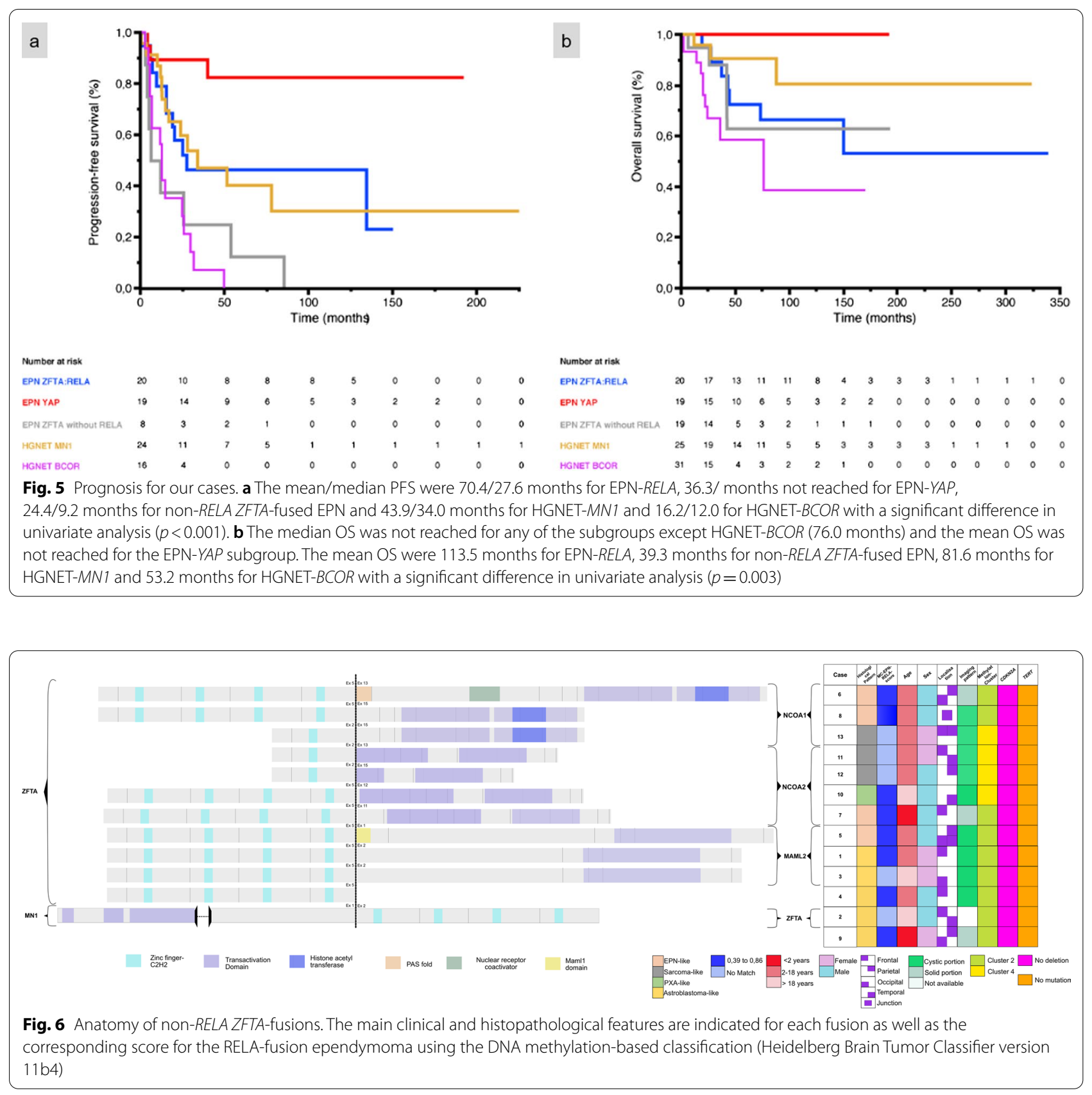

molecularly defined CNS entities are needed to draw a conclusion on the sensitivity/specificity of this biomarker. The landscape of gene partners of ZFTA-fused EPN (without RELA) is wide, the main being MAML2 (21/51 cases), NCOA2 (14/51 cases), and NCOA1 (9/51 cases) genes [6-9]. These fusions alone are sufficient to drive tumorigenesis in vivo $[6,7,9]$. In the original report, the main cases of ZFTA:MAML2 fusion were in cluster 2 and showed ependymal features [9]. Our data are in line with this report as our three cases with ZFTA:MAML2 were classified as cluster 2 and showed a histological phenotype of EPN but also of astroblastoma. A MN1:ZFTA fusion with ZFTA as a 3' partner was noted for the first time in another of our cases, as was previously reported in one case with LTBP3:ZFTA fusion [4]. Interestingly, this case of MN1:ZFTA fusion presented astroblastoma-like features, but was in close vicinity of the MC EPN-RELA (cluster 2) and not HGNET-MN1. The MN1 breakpoint is similar to that of the MN1:BEND2 fusion, which could constitute a diagnostic pitfall if only the MN1 breakapart 


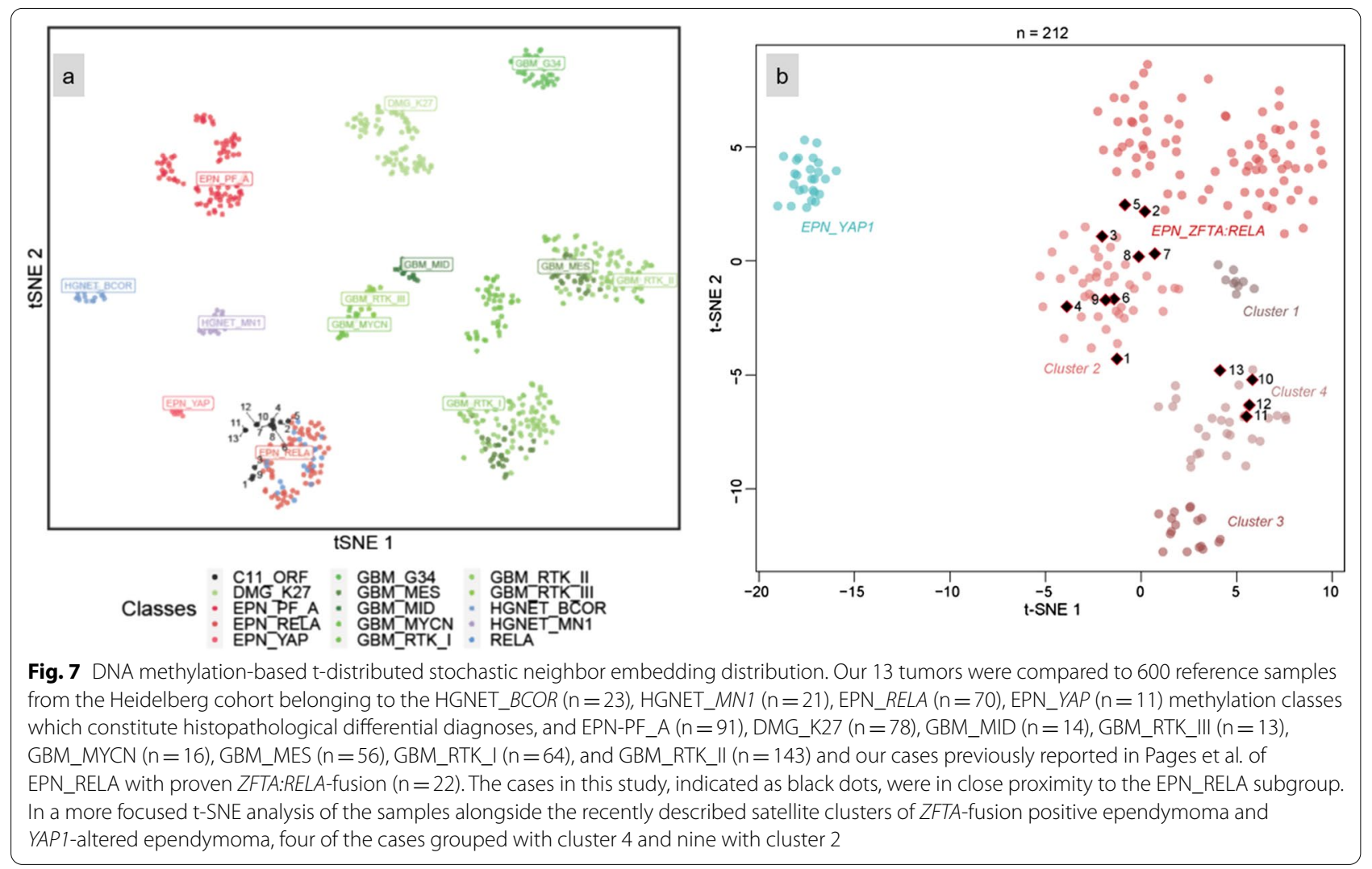

FISH is used. We found a ZFTA fusion with a non-coding region which probably leads to a truncated ZFTA protein at the $C$ terminal end. At the mRNA level, the truncation of 3'UTR of ZFTA eliminates three miRNA binding sites (hsa-miR-424-3p URS00002BCF86_9606) involved in regulating ZFTA expression. This loss of regulation could lead to a nuclear accumulation of ZFTA sustaining oncogenicity with a cis-acting mechanism instead of the trans-activating mechanism that could not take place in the absence of a coactivating partner. This cis-acting mechanism has been suggested by Zhu et al. because only half of the top-scoring ChiP-seq peaks of ZFTA-RELA chimeric proteins containing one or more ZFTA DNA binding motifs [27]. They hypothesized that the no-motif peaks might be bound by a ZFTA-RELA-containing protein complex that uses another pioneer subunit to initiate chromatin binding, necessitating a cis-acting mechanism. In our case, this ZFTA truncation led to an astroblastic phenotype that could correspond to the purely oncogenic cis-effect of ZFTA. This cis-acting hypothesis should be tested in mechanistic studies that are beyond the scope of our descriptive study. It is interesting to note that in our series with detailed histological typing, none of the ZFTA:NCOA1/2 fusions showed any astroblastoma phenotype, which highlights the potential role of the ZFTA partner in the histological phenotype. However, the number of ZFTA zinc fingers is also important. Previous studies have shown that the number of ZFTA zinc fingers in ZFTA:RELA fusions impact oncogenicity as well as the chromatin binding sites [28]. In ZFTA:RELA fusions, the 5'ZFTA part of the chimeric protein has one (RELAfus1) or two (RELAfus2) zinc finger domains while RELA is consistently almost full length. Parker et al. showed that neural stem cells (NSCs) transduced with RELAfus 1 generated tumors after intra-cerebral implantation in nude mice [4]. RELAfus2 NSCs also generated tumors albeit with clearly lower lethality. Using ChiP sequencing, Zhu et al. showed that chimeric protein RELAfus1 binds to 32,135 binding sites, RELAfus2 to 13,954 with only 5338 common sites with fus1 [27]. Therefore, the number of zinc finger domains in the ZFTA fusion necessarily impact the tumoral biology together with the fusion partner. Four ZFTA zinc finger domains is the rule in cases of non-RELA ZFTA-fused EPN published so far [6-9] and this was present in ten of our cases. However, whereas four ZFTA:NCOA1/2 with four zinc fingers corresponded to three classical ependymal histomorphologies and one PXA-like morphology, all three of our ZFTA:NCOA1/2 fusions with only one zinc finger corresponded to a sarcoma-like phenotype. We are the first to 
report such cases and it remains to be confirmed whether a sarcoma phenotype together with a cluster 4 of ST EPN is consistently related to this type of fusion. Retrospective molecular studies of tumors initially diagnosed as primitive CNS sarcomas would be useful to answer this question. Our study and the data in the literature indicate that the outcome is the worst for patients with ST non-RELA $Z F T A$-fused EPN. When the PFS and OS are compared with their ZFTA:RELA-fused counterparts, we noticed a significant difference between the two ST EPN subgroups for PFS but not for OS. However, these results are limited by the low number of reported cases and further studies concerning the prognosis and histopathologic phenotype of the ST ZFTA-fused EPN subgroups are required.

In conclusion, our series characterizes a cohort of ST non-RELA ZFTA-fused EPN which present a large spectrum of histopathological features, including some overlapping with, ZFTA:RELA-fused EPN and poorly differentiated tumors with sarcoma-like features. Despite this heterogeneity, DNA methylation profiling confirmed their epigenetic proximity to the MC EPN-RELA and were subclassified in clusters 2 and 4 . Regardless of the morphology, EMA and L1CAM immunopositivity (without NFKB expression) in ST tumors may incite neuropathologists to suggest this diagnosis. Our work highlighted the usefulness of ZFTA FISH analysis to confirm the existence of a rearrangement without RELA abnormality.

\section{Abbreviations}

DMG: Diffuse midline glioma; EPN: Ependymoma; GBM: Glioblastoma; HGNET: High-grade neuroepithelial tumor; MES: Mesenchymal; MID: Midline; PF_A: Posterior fossa subgroup A.

\section{Supplementary Information}

The online version contains supplementary material available at https://doi. org/10.1186/s40478-021-01238-y.
Additional file 1.
Additional file 2.
Additional file 3. Sanger sequencing of RT-PCR products for MN1:ZFTA fusion.
Additional file 4
Additional file 5. Copy number variation profile of case \#1. Additional file 6. Copy number variation profile of case \#2. Additional file 7. Copy number variation profile of case \#3. Additional file 8. Copy number variation profile of case \#4. Additional file 9. Copy number variation profile of case \#5. Additional file 10. Copy number variation profile of case \#6. Additional file 11. Copy number variation profile of case \#7. Additional file 12. Copy number variation profile of case \#8. Additional file 13. Copy number variation profile of case \#9.

Additional file 14. Copy number variation profile of case \#10.

Additional file 15. Copy number variation profile of case \#11.

Additional file 16. Copy number variation profile of case \#12.

Additional file 17. Copy number variation profile of case \#13.

\section{Acknowledgements}

We would like to thank the laboratory technicians at the GHU Paris Neuro Sainte-Anne for their assistance, as well as the Integragen platform for their technical assistance with DNA-methylation analyses and the RENOCLIP-LOC. The RENOCLIP-LOC is the clinico-pathologic network that is instrumental in the central histopathologic review supported by the Institut National du Cancer (INCa). We thank the association "111 des arts" for financial support for RNA sequencing.

\section{Authors' contributions}

ATE, EL, FC, MP, EUC, AS, AV, FA and PV conducted the neuropathological examinations; EUC, YN, AS, ATE, RS and PS conducted the molecular studies; ATE, LH, EW, EUC, YN, AS, and PV drafted the manuscript; NB and VDR reviewed all imaging data; JP, SP, TB, KB, CP, JG, LGR, SA, CD, PL, MC, AR, CB, ED, MCM, SM, $\mathrm{FLG}$, and FB recruited patients, provided samples and clinical information. All authors reviewed the manuscript.

\section{Funding}

No funding.

\section{Declarations}

\section{Competing interests}

The authors declare that they have no conflict of interest directly related to the topic of this article.

\section{Author details}

'Department of Neuropathology, GHU Paris-Psychiatrie et Neurosciences, Sainte-Anne Hospital, 1, rue Cabanis, 75014 Paris, France. ${ }^{2}$ Institut de Psychiatrie et Neurosciences de Paris (IPNP), UMR S1266, INSERM, IMA-BRAIN, Paris, France. ${ }^{3}$ Université de Paris, Paris, France. ${ }^{4}$ Department of Pathology, Toulouse University Hospital, Toulouse, France. ${ }^{5}$ INSERM U1037, Cancer Research Center of Toulouse (CRCT), Toulouse, France. ${ }^{6}$ Université Paul Sabatier, Toulouse III, Toulouse, France. ${ }^{7}$ U981, Molecular Predictors and New Targets in Oncology, INSERM, Gustave Roussy, Université Paris-Saclay, 94805 Villejuif, France. ${ }^{8}$ Department of Child and Adolescent Oncology, Gustave Roussy, Villejuif, France. ${ }^{9}$ Department of Neuropathology, Institute of Pathology, University Hospital Heidelberg, Heidelberg, Germany. ${ }^{10} \mathrm{Clinical}$ Cooperation Unit Neuropathology, German Consortium for Translational Cancer Research (DKTK), German Cancer Research Center DKFZ, Heidelberg, Germany. ${ }^{11}$ Department of Pathology and Neuropathology, GHE, Hospices Civils de Lyon, Lyon, France. ${ }^{12}$ Department of Neurosurgery, GHU Paris-Psychiatrie et Neurosciences, Sainte-Anne Hospital, Paris, France. ${ }^{13}$ Department of Pathology, Tours Hospital, Tours, France. ${ }^{14}$ Department of Pathology, Angers Hospital, Angers, France. ${ }^{15}$ Department of Oncology, Pontchaillou Hospital, Rennes, France. ${ }^{16}$ Institute of Pediatric Hematology and Oncology (IHOPe), Centre Léon Bérard, Lyon, France. ${ }^{17}$ Department of Pediatric Oncology, Institut Curie, Paris, France. ${ }^{18}$ Gustave Roussy Cancer Center and Paris-Saclay University, «Genomics and Oncogenesis of Pediatric Brain Tumors» INSERM U981, Villejuif, France.

${ }^{19}$ Pediatric Radiology Department, AP-HP, Hôpital Universitaire Necker-Enfants Malades, 75015 Paris, France. ${ }^{20}$ Université de Paris, INSERM ERL UA10, INSERM U1 163, Institut Imagine, 75015 Paris, France. ${ }^{21}$ Department of Biochemistry and Oncogenetics, Paul Brousse Hospital, 94804 Villejuif, France. ${ }^{22}$ Department of Pediatric Neurosurgery, Necker Hospital, APHP, Université Paris Descartes, Sorbonne Paris Cité, Paris, France.

Received: 24 June 2021 Accepted: 5 August 2021

Published online: 13 August 2021 


\section{References}

1. Pajtler KW, Witt H, Sill M, Jones DTW, Hovestadt V, Kratochwil F, Wani K, Tatevossian R, Punchihewa C, Johann P, Reimand J, Warnatz H-J, Ryzhova M, Mack S, Ramaswamy V, Capper D, Schweizer L, Sieber L, Wittmann A, Huang Z, van Sluis P, Volckmann R, Koster J, Versteeg R, Fults D, Toledano $H$, Avigad S, Hoffman LM, Donson AM, Foreman N, Hewer E, Zitterbart K, Gilbert M, Armstrong TS, Gupta N, Allen JC, Karajannis MA, Zagzag D, Hasselblatt M, Kulozik AE, Witt O, Collins VP, von Hoff K, Rutkowski S, Pietsch T, Bader G, Yaspo M-L, von Deimling A, Lichter P, Taylor MD, Gilbertson R, Ellison DW, Aldape K, Korshunov A, Kool M, Pfister SM (2015) Molecular classification of ependymal tumors across all CNS compartments, histopathological grades, and age groups. Cancer Cell 27:728-743. https://doi. org/10.1016/j.ccell.2015.04.002

2. Andreiuolo $F$, Varlet $P$, Tauziède-Espariat $A$, Jünger ST, Dörner $E$, Dreschmann V, Kuchelmeister K, Waha A, Haberler C, Slavc I, Corbacioglu S, Riemenschneider MJ, Leipold A, Rüdiger T, Körholz D, Acker T, Russo A, Faber J, Sommer C, Armbrust S, Rose M, Erdlenbruch B, Hans VH, Bernbeck B, Schneider D, Lorenzen J, Ebinger M, Handgretinger R, Neumann M, van Buiren M, Prinz M, Roganovic J, Jakovcevic A, Park S-H, Grill J, Puget S, Messing-Jünger M, Reinhard H, Bergmann M, Hattingen E, Pietsch T (2019) Childhood supratentorial ependymomas with YAP1-MAMLD1 fusion: an entity with characteristic clinical, radiological, cytogenetic and histopathological features. Brain Pathol Zurich Switz 29:205-216. https:// doi.org/10.1111/bpa.12659

3. Pagès M, Pajtler KW, Puget $S$, Castel $D$, Boddaert $N$, Tauziède-Espariat A, Picot S, Debily M-A, Kool M, Capper D, Sainte-Rose C, Chrétien F, Pfister SM, Pietsch T, Grill J, Varlet P, Andreiuolo F (2019) Diagnostics of pediatric supratentorial RELA ependymomas: integration of information from histopathology, genetics, DNA methylation and imaging. Brain Pathol Zurich Switz 29:325-335. https://doi.org/10.1111/bpa.12664

4. Parker M, Mohankumar KM, Punchihewa C, Weinlich R, Dalton JD, Li Y, Lee R, Tatevossian RG, Phoenix TN, Thiruvenkatam R, White E, Tang B, Orisme W, Gupta K, Rusch M, Chen X, Li Y, Nagahawhatte P, Hedlund E, Finkelstein D, Wu G, Shurtleff S, Easton J, Boggs K, Yergeau D, Vadodaria B, Mulder HL, Becksfort J, Becksford J, Gupta P, Huether R, Ma J, Song G, Gajjar A, Merchant T, Boop F, Smith AA, Ding L, Lu C, Ochoa K, Zhao D, Fulton RS, Fulton LL, Mardis ER, Wilson RK, Downing JR, Green DR, Zhang J, Ellison DW, Gilbertson RJ (2014) C11 orf95-RELA fusions drive oncogenic NF-KB signalling in ependymoma. Nature 506:451-455. https://doi.org/10.1038/ nature13109

5. Ellison DW, Aldape KD, Capper D, Fouladi M, Gilbert MR, Gilbertson RJ, Hawkins C, Merchant TE, Pajtler K, Venneti S, Louis DN (2020) CIMPACTNOW update 7: advancing the molecular classification of ependymal tumors. Brain Pathol Zurich Switz 30:863-866. https://doi.org/10.1111/ bpa.12866

6. Tamai S, Nakano Y, Kinoshita M, Sabit H, Nobusawa S, Arai Y, Hama N, Totoki Y, Shibata T, Ichimura K, Nakada M (2021) Ependymoma with C11orf95-MAML2 fusion: presenting with granular cell and ganglion cell features. Brain Tumor Pathol 38:64-70. https://doi.org/10.1007/ s10014-020-00388-6

7. Tomomasa R, Arai Y, Kawabata-Iwakawa R, Fukuoka K, Nakano Y, Hama N, Nakata S, Suzuki N, Ishi Y, Tanaka S, Takahashi JA, Yuba Y, Shiota M, Natsume A, Kurimoto M, Shiba Y, Aoki M, Nabeshima K, Enomoto T, Inoue T, Fujimura J, Kondo A, Yao T, Okura N, Hirose T, Sasaki A, Nishiyama M, Ichimura K, Shibata T, Hirato J, Yokoo H, Nobusawa S (2021) Ependymoma-like tumor with mesenchymal differentiation harboring C11 orf95-NCOA1/2 or -RELA fusion: a hitherto unclassified tumor related to ependymoma. Brain Pathol Zurich Switz. https://doi.org/10.1111/bpa. 12943

8. Zschernack V, Jünger ST, Mynarek M, Rutkowski S, Garre ML, Ebinger M, Neu M, Faber J, Erdlenbruch B, Claviez A, Bielack S, Brozou T, Frühwald MC, Dörner E, Dreschmann V, Stock A, Solymosi L, Hench J, Frank S, Vokuhl C, Waha A, Andreiuolo F, Pietsch T (2021) Supratentorial ependymoma in childhood: more than just RELA or YAP. Acta Neuropathol (Berl) 141:455-466. https://doi.org/10.1007/s00401-020-02260-5

9. Zheng T, Ghasemi DR, Okonechnikov K, Korshunov A, Sill M, Maass KK, Goncalves B, da Silva P, Ryzhova M, Gojo J, Stichel D, Arabzade A, Kupp R, Benzel J, Taya S, Adachi T, Shiraishi R, Gerber NU, Sturm D, Ecker J, Sievers P, Selt F, Chapman R, Haberler C, Figarella-Branger D, Reifenberger G, Fleischhack G, Rutkowski S, Donson AM, Ramaswamy V, Capper D, Ellison DW, Herold-Mende CC, Schuller U, Brandner S, Hernaiz Driever P, Kros JM,
Snuderl M, Milde T, Grundy RG, Hoshino M, Mack SC, Gilbertson RJ, Jones DTW, Kool M, von Deimling A, Pfister SM, Sahm F, Kawauchi D, Pajtler KW (2021) Cross-species genomics reveals oncogenic dependencies in ZFTA/ C11 orf95 fusion-positive supratentorial ependymomas. Cancer Discov. https://doi.org/10.1158/2159-8290.CD-20-0963

10. Al-Battashi A, Al Hajri Z, Perry A, Al-Kindi H, Al-Ghaithi I (2019) A cerebellar high-grade neuroepithelial tumour with BCOR alteration in a five-yearold child: a case report. Sultan Qaboos Univ Med J 19:e153-e156. https:// doi.org/10.18295/squmj.2019.19.02.012

11. Appay R, Macagno N, Padovani L, Korshunov A, Kool M, André N, Scavarda D, Pietsch T, Figarella-Branger D (2017) HGNET-BCOR tumors of the cerebellum: clinicopathologic and molecular characterization of 3 cases. Am J Surg Pathol 41:1254-1260. https://doi.org/10.1097/PAS.0000000000 000866

12. Boisseau W, Euskirchen $P$, Mokhtari $K$, Dehais $C$, Touat $M$, Hoang-Xuan K, Sanson M, Capelle L, Nouet A, Karachi C, Bielle F, Guégan J, Marie Y, Martin-Duverneuil N, Taillandier L, Rousseau A, Delattre J-Y, Idbaih A (2019) Molecular profiling reclassifies adult astroblastoma into known and clinically distinct tumor entities with frequent mitogen-activated protein kinase pathway alterations. Oncologist. https://doi.org/10.1634/ theoncologist.2019-0223

13. Bremer J, Kottke R, Johann PD, von Hoff K, Brazzola P, Grotzer MA, Kool M, Rushing E, Gerber NU (2020) A single supratentorial high-grade neuroepithelial tumor with two distinct BCOR mutations, exceptionally long complete remission and survival. Pediatr Blood Cancer. https://doi.org/10. 1002/pbc.28384

14. Ferris SP, Velazquez Vega J, Aboian M, Lee JC, Van Ziffle J, Onodera C, Grenert JP, Saunders T, Chen Y-Y, Banerjee A, Kline CN, Gupta N, Raffel C, Samuel D, Ruiz-Diaz I, Magaki S, Wilson D, Neltner J, Al-Hajri Z, Phillips JJ, Pekmezci M, Bollen AW, Tihan T, Schniederjan M, Cha S, Perry A, Solomon DA (2019) High-grade neuroepithelial tumor with BCOR exon 15 internal tandem duplication - a comprehensive clinical, radiographic, pathologic, and genomic analysis. Brain Pathol Zurich Switz. https://doi.org/10.1111/ bpa. 12747

15. Fukuoka K, Kanemura Y, Shofuda T, Fukushima S, Yamashita S, Narushima D, Kato M, Honda-Kitahara M, Ichikawa H, Kohno T, Sasaki A, Hirato J, Hirose T, Komori T, Satomi K, Yoshida A, Yamasaki K, Nakano Y, Takada A, Nakamura T, Takami H, Matsushita Y, Suzuki T, Nakamura H, Makino K, Sonoda Y, Saito R, Tominaga T, Matsusaka Y, Kobayashi K, Nagane M, Furuta T, Nakada M, Narita Y, Hirose Y, Ohba S, Wada A, Shimizu K Kurozumi K, Date I, Fukai J, Miyairi Y, Kagawa N, Kawamura A, Yoshida M, Nishida N, Wataya T, Yamaoka M, Tsuyuguchi N, Uda T, Takahashi M, Nakano Y, Akai T, Izumoto S, Nonaka M, Yoshifuji K, Kodama Y, Mano M, Ozawa T, Ramaswamy V, Taylor MD, Ushijima T, Shibui S, Yamasaki M, Arai H, Sakamoto H, Nishikawa R, Ichimura K, Japan Pediatric Molecular Neuro-Oncology Group (JPMNG) (2018) Significance of molecular classification of ependymomas: C11 orf95-RELA fusion-negative supratentorial ependymomas are a heterogeneous group of tumors. Acta Neuropathol Commun 6:134. https://doi.org/10.1186/s40478-018-0630-1

16. Kirkman MA, Pickles JC, Fairchild AR, Avery A, Pietsch T, Jacques TS, Aquilina K (2018) Early wound site seeding in a patient with central nervous system high-grade neuroepithelial tumor with BCOR alteration. World Neurosurg 116:279-284. https://doi.org/10.1016/j.wneu.2018.05.158

17. Lehman NL, Usubalieva A, Lin T, Allen SJ, Tran QT, Mobley BC, McLendon RE, Schniederjan MJ, Georgescu M-M, Couce M, Dulai MS, Raisanen JM, Al Abbadi M, Palmer CA, Hattab EM, Orr BA (2019) Genomic analysis demonstrates that histologically-defined astroblastomas are molecularly heterogeneous and that tumors with MN1 rearrangement exhibit the most favorable prognosis. Acta Neuropathol Commun 7:42. https://doi. org/10.1186/s40478-019-0689-3

18. Petruzzellis G, Alessi I, Colafati GS, Diomedi-Camassei F, Ciolfi A, Pedace L, Cacchione A, Carai A, Tartaglia M, Mastronuzzi A, Miele E (2019) Role of DNA methylation profile in diagnosing astroblastoma: a case report and literature review. Front Genet. https://doi.org/10.3389/fgene.2019.00391

19. Sturm D, Orr BA, Toprak UH, Hovestadt V, Jones DTW, Capper D, Sill M, Buchhalter I, Northcott PA, Leis I, Ryzhova M, Koelsche C, Pfaff E, Allen SJ, Balasubramanian G, Worst BC, Pajtler KW, Brabetz S, Johann PD, Sahm F, Reimand J, Mackay A, Carvalho DM, Remke M, Phillips JJ, Perry A, Cowdrey C, Drissi R, Fouladi M, Giangaspero F, Łastowska M, Grajkowska W, Scheurlen W, Pietsch T, Hagel C, Gojo J, Lötsch D, Berger W, Slavc I, Haberler C, Jouvet A, Holm S, Hofer S, Prinz M, Keohane C, Fried I, Mawrin 
C, Scheie D, Mobley BC, Schniederjan MJ, Santi M, Buccoliero AM, Dahiya S, Kramm CM, von Bueren AO, von Hoff K, Rutkowski S, Herold-Mende C, Frühwald MC, Milde T, Hasselblatt M, Wesseling P, Rößler J, Schüller U, Ebinger M, Schittenhelm J, Frank S, Grobholz R, Vajtai I, Hans V, Schneppenheim R, Zitterbart K, Collins VP, Aronica E, Varlet P, Puget S, Dufour C, Grill J, Figarella-Branger D, Wolter M, Schuhmann MU, Shalaby T, Grotzer M, van Meter T, Monoranu C-M, Felsberg J, Reifenberger G, Snuderl M, Forrester LA, Koster J, Versteeg R, Volckmann R, van Sluis P, Wolf S, Mikkelsen T, Gajjar A, Aldape K, Moore AS, Taylor MD, Jones C, Jabado N, Karajannis MA, Eils R, Schlesner M, Lichter P, von Deimling A, Pfister SM, Ellison DW, Korshunov A, Kool M (2016) New brain tumor entities emerge from molecular classification of CNS-PNETs. Cell 164:1060-1072. https:// doi.org/10.1016/j.cell.2016.01.015

20. Tauziède-Espariat $A$, Pagès $M$, Roux $A$, Siegfried A, Uro-Coste E, Nicaise Y, Sevely A, Gambart M, Boetto S, Dupuy M, Richard P, Perbet R, Vinchon M, Caron S, Andreiuolo F, Gareton A, Lechapt E, Chrétien F, Puget S, Grill J, Boddaert N, Varlet P, RENOCLIP-LOC, (2019) Pediatric methylation class HGNET-MN1: unresolved issues with terminology and grading. Acta Neuropathol Commun 7:176. https://doi.org/10.1186/s40478-019-0834-z

21. Wood MD, Tihan T, Perry A, Chacko G, Turner C, Pu C, Payne C, Yu A, Bannykh SI, Solomon DA (2018) Multimodal molecular analysis of astroblastoma enables reclassification of most cases into more specific molecular entities. Brain Pathol Zurich Switz 28:192-202. https://doi.org/10.1111/ bpa.12561

22. Yoshida Y, Nobusawa S, Nakata S, Nakada M, Arakawa Y, Mineharu Y, Sugita Y, Yoshioka T, Araki A, Sato Y, Takeshima H, Okada M, Nishi A, Yamazaki T, Kohashi K, Oda Y, Hirato J, Yokoo H (2018) CNS high-grade neuroepithelial tumor with BCOR internal tandem duplication: a comparison with its counterparts in the kidney and soft tissue. Brain Pathol Zurich Switz 28:710-720. https://doi.org/10.1111/bpa.12585

23. Pagès M, Beccaria K, Boddaert N, Saffroy R, Besnard A, Castel D, Fina F, Barets D, Barret E, Lacroix L, Bielle F, Andreiuolo F, Tauziède-Espariat A, Figarella-Branger D, Puget S, Grill J, Chrétien F, Varlet P (2016) Cooccurrence of histone H3 K27M and BRAF V600E mutations in paediatric midline grade I ganglioglioma. Brain Pathol Zurich Switz. https://doi.org/ 10.1111/bpa.12473

24. Capper D, Jones DTW, Sill M, Hovestadt V, Schrimpf D, Sturm D, Koelsche C, Sahm F, Chavez L, Reuss DE, Kratz A, Wefers AK, Huang K, Pajtler KW, Schweizer L, Stichel D, Olar A, Engel NW, Lindenberg K, Harter PN, Braczynski AK, Plate KH, Dohmen H, Garvalov BK, Coras R, Hölsken A, Hewer E, Bewerunge-Hudler M, Schick M, Fischer R, Beschorner R, Schittenhelm J, Staszewski O, Wani K, Varlet P, Pages M, Temming P, Lohmann D, Selt F, Witt H, Milde T, Witt O, Aronica E, Giangaspero F, Rushing E, Scheurlen W, Geisenberger C, Rodriguez FJ, Becker A, Preusser M, Haberler C, Bjerkvig R, Cryan J, Farrell M, Deckert M, Hench J, Frank S, Serrano J, Kannan K,
Tsirigos A, Brück W, Hofer S, Brehmer S, Seiz-Rosenhagen M, Hänggi $D$, Hans V, Rozsnoki S, Hansford JR, Kohlhof P, Kristensen BW, Lechner M, Lopes B, Mawrin C, Ketter R, Kulozik A, Khatib Z, Heppner F, Koch A, Jouvet A, Keohane C, Mühleisen H, Mueller W, Pohl U, Prinz M, Benner A, Zapatka M, Gottardo NG, Driever PH, Kramm CM, Müller HL, Rutkowski S, von Hoff K, Frühwald MC, Gnekow A, Fleischhack G, Tippelt S, Calaminus G, Monoranu C-M, Perry A, Jones C, Jacques TS, Radlwimmer B, Gessi M, Pietsch T, Schramm J, Schackert G, Westphal M, Reifenberger G, Wesseling P, Weller M, Collins VP, Blümcke I, Bendszus M, Debus J, Huang A, Jabado N, Northcott PA, Paulus W, Gajjar A, Robinson GW, Taylor MD, Jaunmuktane Z, Ryzhova M, Platten M, Unterberg A, Wick W, Karajannis MA, Mittelbronn M, Acker T, Hartmann C, Aldape K, Schüller U, Buslei R, Lichter P, Kool M, Herold-Mende C, Ellison DW, Hasselblatt M, Snuderl M, Brandner S, Korshunov A, von Deimling A, Pfister SM (2018) DNA methylation-based classification of central nervous system tumours. Nature 555:469-474. https://doi.org/10.1038/nature26000

25. Figarella-Branger $D$, Lechapt-Zalcman $E$, Tabouret $E$, Jünger $S$, de Paula AM, Bouvier C, Colin C, Jouvet A, Forest F, Andreiuolo F, Quintin-Roue I, Machet M-C, Heitzmann A, Milin S, Sevestre H, Godfraind C, Labrousse F, Metellus P, Scavarda D, Pietsch T (2016) Supratentorial clear cell ependymomas with branching capillaries demonstrate characteristic clinicopathological features and pathological activation of nuclear factorkappaB signaling. Neuro Oncol 18:919-927. https://doi.org/10.1093/ neuonc/now025

26. Gessi M, Giagnacovo M, Modena P, Elefante G, Gianno F, Buttarelli FR, Arcella A, Donofrio V, Diomedi Camassei F, Nozza P, Morra I, Massimino M, Pollo B, Giangaspero F, Antonelli M (2019) Role of immunohistochemistry in the identification of supratentorial C11ORF95-RELA fused ependymoma in routine neuropathology. Am J Surg Pathol 43:56-63. https:// doi.org/10.1097/PAS.00000000000000979

27. Zhu JJ, Jillette N, Li X-N, Cheng AW, Lau CC (2020) C11 orf95-RELA reprograms 3D epigenome in supratentorial ependymoma. Acta Neuropathol (Berl) 140:951-960. https://doi.org/10.1007/s00401-020-02225-8

28. Kupp R, Ruff L, Terranova S, Nathan E, Ballereau S, Stark R, Sekhar Reddy Chilamakuri C, Hoffmann N, Wickham-Rahrmann K, Widdess M, Arabzade A, Zhao Y, Varadharajan S, Zheng T, Murugesan MK, Pfister SM, Kawauchi D, Pajtler KW, Deneen B, Mack SC, Masih KE, Gryder BE, Khan J, Gilbertson RJ (2021) ZFTA-translocations constitute ependymoma chromatin remodeling and transcription factors. Cancer Discov. https://doi.org/10. 1158/2159-8290.CD-20-1052

\section{Publisher's Note}

Springer Nature remains neutral with regard to jurisdictional claims in published maps and institutional affiliations.
Ready to submit your research? Choose BMC and benefit from:

- fast, convenient online submission

- thorough peer review by experienced researchers in your field

- rapid publication on acceptance

- support for research data, including large and complex data types

- gold Open Access which fosters wider collaboration and increased citations

- maximum visibility for your research: over $100 \mathrm{M}$ website views per year

At BMC, research is always in progress.

Learn more biomedcentral.com/submissions 